\title{
LICENSE AUCTIONS WITH ROYALTY CONTRACTS FOR (WINNERS AND) LOSERS ${ }^{1}$
}

\author{
THOMAS GIEBE ELMAR WOLFSTETTER \\ Institute of Economic Theory I, Humboldt University at Berlin \\ Spandauer Str. 1, 10099 Berlin, Germany \\ Email: thomas.giebe@wiwi.hu-berlin.de \\ elmar.wolfstetter@rz.hu-berlin.de
}

Tel: +49-30-2093-5652, Fax: +49-30-2093-5619

APRIL (REVISED) 2007

\footnotetext{
${ }^{1}$ We thank Tim Grebe, Hendrik Hakenes, Kai Konrad, Yvan Lengwiler, Benny Moldovanu, Claudia Wernecke, and in particular the anonymous referees for comments. Financial support from the Deutsche Forschungsgemeinschaft, SFB Transregio 15: "Governance and the Efficiency of Economic Systems", is gratefully acknowledged.
} 


\begin{abstract}
This paper revisits the licensing of a non-drastic process innovation by an outside innovator to a Cournot oligopoly. We propose a new mechanism that combines a restrictive license auction with royalty licensing. This mechanism is more profitable than standard license auctions, auctioning royalty contracts, fixed-fee licensing, pure royalty licensing, and two-part tariffs. The key features are that royalty contracts are auctioned and that losers of the auction are granted the option to sign a royalty contract. Remarkably, combining royalties for winners and losers makes the integer constraint concerning the number of licenses irrelevant.
\end{abstract}

JEL classifications: D21, D43, D44, D45.

Keywords: Patents, Licensing, Auctions, Royalty, Innovation, R\&D, Mechanism Design. 


\section{INTRODUCTION}

This paper revisits the standard analysis of licensing an outside innovator's cost reducing innovation to a Cournot oligopoly. We propose a simple new mechanism that combines a license auction with royalty licensing in a particular way. This new mechanism is more profitable than the standard solutions evaluated in the literature such as standard license auctions, auctioning royalty contracts, fixed-fee licensing, pure royalty licensing, and two-part tariffs (see Kamien, 1992, Kamien and Tauman, 1984, 1986, Katz and Shapiro, 1985, 1986, Sen and Tauman, 2007).

The two key features of the proposed mechanism are that it grants the losers of the license auction the option to sign a royalty contract, and that it employs a royalty component in the auctioned contract. Like in the standard auction, the innovator auctions a restricted number of licenses; but, the auctioned licenses are royalty contracts, and, after the auction, those who lose the auction are granted the option to sign a pure royalty contract.

In equilibrium, the innovator sets the royalty rate for losers equal to the marginal cost reduction induced by the innovation. As a result, the royalty licensing granted in the second stage, after the auction, has no effect on equilibrium bids since losers of the auction have the same payoff functions as if no royalty option had been granted. Furthermore, in equilibrium the number of auctioned licenses is such that no loser is crowded out of the market. Thus, royalty income is collected which explains in part the superiority of the proposed mechanism.

Our analysis also takes into account that the number of licenses must be an integer which is particularly important if a small number of firms is involved. Here, the royalty component in the auctioned contracts comes into the picture as a tool for fine tuning. Essentially, that royalty component is used to implement the optimal mechanism without violating the integer constraint.

Recently, Sen (2005) showed that this integer constraint can make pure royalty contracts superior to the standard license auction, contrary to a standard result of the literature. However, in our more general framework that integer constraint can be satisfied at no loss in profit.

The literature on patent licensing in oligopoly has branched out in various directions. Sen and Tauman (2007) analyzed an auction of royalty contracts. Wang (1998) and Kamien and Tauman (2002) analyzed the licensing problem from the perspective of an innovator who is also an incumbent player in the downstream product market. While an outside innovator is only interested in licensing income, an "inside" innovator must also take into account how giving access to his innovation affects his own downstream profit.

Muto (1993), Hernández-Murillo and Llobet (2006) dealt with other market games such as Bertrand or monopolistic competition with product differentiation in lieu of the Cournot competition assumed here. And Beggs (1992), Gallini and Wright (1990), Macho-Stadler and Pérez-Castrillo (1991) examined the benefits of royalty licensing either as a screening device in the face 
of incomplete information concerning the users' willingness to pay for the innovation or as a signaling device if the innovator has superior information concerning the cost reduction induced by his innovation. Jehiel and Moldovanu (2000) analyzed single-unit auctions that cause externalities in an aftermarket. Our results are also driven by the fact that the outcome of the auction affects competition in the subsequent Cournot market.

The licensing policy proposed in the present paper stipulates royalty payments from all firms, and price discrimination between firms by offering different combinations of royalty rates and fixed fees. This raises the question: are royalty rates and discrimination employed in industry? Unfortunately, the empirical literature on licensing practices does not provide sufficient evidence to fully answer this question. A widely cited study of U.S. firms observes that "A down payment with running royalties method was used $46 \%$ of the time, while straight royalties and paid-up licenses accounted for $39 \%$ and 13\%, respectively" (Rostoker, 1984, p.64). This finding is often interpreted as proving the predominance of royalty licensing (see also the study on foreign technology licensing to Indian firms by Vishwasrao (2007)). ${ }^{1}$ That study also reports that the same innovator often employs different licensing schemes, possibly for licensing the same innovation to different customers. Moreover, casual evidence suggests that discrimination is widely used in software licensing and in the sale of innovative products. A case in point is the "Original Equipment Manufacturer (OEM) Licensing" where PC manufacturers are charged different prices and sometimes are given a choice between a "one-time paid-up" license, which entitles the manufacturer to unlimited distribution of the software within a specified time period, and a per copy royalty license.

Similarly, new products are often sold to some users for unrestricted use while others are offered a leasing contract which is effectively a royalty licensing scheme. The only difference between these arrangements and the one proposed here is that customers are typically free to choose between these two arrangements, whereas the proposed policy assumes that the innovator limits that choice by offering a restricted number of licenses.

The plan of the paper is as follows. In Section 2. we state the licensing problem as a sequential game and introduce basic assumptions. Section 3. summarizes some general properties of the equilibrium, and Section 4. derives the optimal mechanism and explains the role of the integer constraint on the number of contracts. Section 5. offers a discussion of the main results and explores various extensions.

\section{THE MODEL}

There are $n \geq 2$ firms with the linear cost function $C_{i}\left(q_{i}\right):=c q_{i}, c>0$, and the inverse demand function $P(Q)$ with $Q:=\sum_{i=1}^{n} q_{i}$. They play a Cournot

\footnotetext{
${ }^{1}$ Royalty contracts require inspection rates to monitor output. In a recent empirical study, Brousseau et al. (2007) report that "license contracts typically grant inspection rights aimed at controlling the licensee's usage of the licensed technology or to a third party."
} 
game.

An outside innovator owns a patented innovation that reduces the marginal cost from $c$ to $c-\epsilon$ with $c>\epsilon>0$. The innovator can permit the use of that innovation by issuing licenses. In general, a license is a two-part tariff contract, with a royalty rate per output unit and a fixed fee. This covers fixed-fee contracts, pure royalty contracts, and the auctioning of royalty contracts.

Throughout this text we employ the usual notion of a drastic vs. non-drastic innovation. An innovation is drastic if its exclusive use by one firm propels monopolization. Each innovation induces a natural oligopoly of a certain size, denoted by $K$, in the sense that if $K$ or more firms operate with the new technology (at marginal cost $c-\epsilon$ ), all firms with marginal cost $c$ exit, i.e. their equilibrium output is equal to zero because the equilibrium price is below $c$. In this text we assume that the innovation is non-drastic in the sense that $K>1 .^{2}$

The following stage game (under complete information) is played: the innovator chooses a licensing mechanism; then firms play that mechanism as a noncooperative game; finally, firms play a Cournot market game, after having observed the outcome of the previous play, knowing who gained access to the innovation and how.

We introduce the modified license auction $\left(k, r_{w}, r_{l}\right)$. The innovator auctions a limited number of $k$ royalty contracts (possibly with a minimum bid), with the royalty rate $r_{w}<\epsilon$, and gives those firms who lose the auction the option to sign a royalty contract with a royalty rate $r_{l}>0$. Of course, $r_{w}<r_{l}$, and royalty contracts are not accepted if they exceed the cost reduction. ${ }^{3}$

The mechanism $m$ includes all other standard mechanisms considered in the literature as special cases, ranging from fixed-fee licensing, pure royalty licensing, to the auctioning of fixed fee licenses or royalty contracts. For instance, fixed-fee licensing is equivalent to an auction of $k=n$ contracts with $r_{w}=0$ and a minimum bid, and $r_{l}>\epsilon$. Pure royalty licensing is equivalent to $k=0,0<r_{l} \leq \epsilon$. The case $k \in[1, n], r_{w}=0, r_{l}>\epsilon$ is the standard license auction analyzed by Kamien (1992) and others, and with $r_{w}>0$ the auction analyzed by Sen and Tauman (2007).

In the following we refer to those firms who win the auction as "winners" $(w)$ and those who lose as "losers" $(l)$.

The number of contracts $k$ is an integer (which can make a difference but is typically ignored in the literature).

Throughout our analysis, the inverse market demand function $P$ satisfies the following assumptions: ${ }^{4}$

\footnotetext{
${ }^{2}$ The notation is borrowed from Kamien (1992). The case of drastic innovation, $K \leq 1$, is trivial. There, the innovation induces a natural monopoly where issuing one fixed-fee license is optimal.

${ }^{3}$ Note that these restrictions on $r_{w}$ and $r_{l}$ only exclude strategies of the innovator that are obviously not optimal.

${ }^{4}$ These assumptions are similar to those employed in Kamien et al. (1992).
} 
ASSUMPTION 1 Inverse demand $P$ is strictly decreasing in $Q$ and continuously differentiable for $Q>0$, and $P(Q) Q$ is strictly concave in $Q$ and $P(0)>c$, and $P(Q)=0$ for all $Q \geq \bar{Q}>0$ (satiation point).

\section{EQUILIBRIA OF THE COURNOT MARKET AND LICENSING SUBGAMES}

The equilibrium concept is that of a subgame perfect Nash equilibrium (SPNE) which is found by backward induction.

COURnOT SUBGAmes The Cournot subgame is an asymmetric oligopoly game played between winners $(w)$ and losers who have exercised the royalty option and potentially those who have no license at all. We focus on the particular subgames with $k$ winners and $n-k$ losers who have exercised the royalty option if and only if $r_{l} \leq \epsilon$. Consequently, the unit costs are changed from $c$ to $c_{w}:=c-\epsilon+r_{w}$, resp. $c_{l}:=c-\epsilon+r_{l}$. At the end of this section we briefly elaborate on the other subgames in which some firms have neither acquired a license nor exercised the royalty option.

Depending on the mechanism, in equilibrium either all losers are crowded out or coexist and produce positive outputs. The critical level of $k$ above which all losers are crowded out depends upon effective unit costs, $c_{l}, c_{w}$. We denote this critical level by $\mathcal{K}\left(r_{w}, r_{l}\right)$, and mention that $\mathcal{K}(0, \epsilon)=K$, i.e. auctioning $\mathcal{K}(0, \epsilon)=K$ licenses establishes a natural oligopoly of size $K$. (Note that in a duopoly crowding out is impossible by assumption of a non-drastic innovation.)

Using the measure $\mathcal{K}\left(r_{w}, r_{l}\right)$ it follows that all firms, winners and losers alike, coexist in the Cournot market if there are less than $n$ winners and $k<\mathcal{K}\left(r_{w}, r_{l}\right)$, whereas only winners are active in the Cournot subgame if $k=n$ or $k>\mathcal{K}\left(r_{w}, r_{l}\right)$.

Note that for $r_{l} \geq \epsilon$ all losers have an effective unit cost equal to $c$ (since a contract with $r>\epsilon$ is never accepted), as in the standard license auction game without royalty contract option studied by Kamien (1992), Kamien et al. (1992) and others.

We denote the equilibrium Cournot outputs by $q_{w}, q_{l}, Q$, and the associated equilibrium profits of firms by $\pi_{w}, \pi_{l}$ :

$$
\begin{aligned}
\pi_{i} & :=\left(P(Q)-c_{i}\right) q_{i}, \quad i \in\{l, w\} \\
Q & :=k q_{w}+(n-k) q_{l}
\end{aligned}
$$

These equilibrium outputs are defined as solutions of the Kuhn-Tucker conditions $\frac{\partial \pi_{i}}{\partial q_{i}} \leq 0, q_{i} \frac{\partial \pi_{i}}{\partial q_{i}}=0, i \in\{w, l\}$. They are functions of $m$, although, with slight abuse of notation, we often use the same symbol for a function and its value, whenever that distinction is evident from the context.

If both winners and losers coexist (i.e. if $q_{l}>0$ ), one can eliminate the variable $q_{w}$ and solve for $\left(Q, q_{l}\right)$ as a function of average marginal cost, $\bar{c}$, 
by writing these conditions in the form ${ }^{5}$

$$
\begin{aligned}
0 & =n P(Q)+Q P^{\prime}(Q)-n \bar{c} \\
0 & =P(Q)+q_{l} P^{\prime}(Q)-c_{l} \\
\bar{c} & :=\frac{k}{n} c_{w}+\frac{n-k}{n} c_{l}
\end{aligned}
$$

Interestingly, $Q$ can be solved uniquely as a function of $\bar{c}$, from (3), and then $q_{l}$ can be computed by plugging $Q$ into (4). Therefore, $Q$ is exclusively a function of $\bar{c}$, and $q_{l}$ is only a function of $\bar{c}$ and $c_{l} .{ }^{6}$

Whereas if losers are crowded out (i.e. if $P(Q)-c_{l} \leq 0$ and hence $q_{l}=$ $0)$, the equilibrium aggregate output solves the obvious condition $k P(Q)+$ $Q P^{\prime}(Q)-k c_{w}=0$ and $q_{w}=Q / k$.

LEMMA 1 Equilibrium aggregate output $Q$ is strictly decreasing in $\bar{c}$. If winners and losers coexist, both $q_{l}$ and $Q$ are (directly or indirectly) decreasing in $c_{l}$. If losers are crowded out, $Q$ is decreasing in $k$ and in $c_{w}$.

Proof Suppose winners and losers coexist. Then, $Q$ uniquely solves the condition $\left(n P(Q)+P^{\prime}(Q) Q\right)=n \bar{c}$. By Assumption $1\left(P(Q)+P^{\prime}(Q) Q\right)$ and $P(Q)$ are decreasing in $Q$; therefore, $\left(n P(Q)+P^{\prime}(Q) Q\right)$ is also decreasing in $Q$. Hence, the equilibrium $Q$ is decreasing in $\bar{c}$. The assertion concerning the effects of $c_{l}$ are obvious. Now suppose losers are crowded out. Then, the market game is a symmetric $k$-firm oligopoly, and it follows immediately that $Q$ is decreasing in $\bar{c}$ and in $k$.

Another key property of the asymmetric oligopoly induced by licensing concerns gross profits $\bar{\pi}_{i}$, i.e. firms' profits before deducting royalty payments:

$$
\begin{aligned}
\bar{\pi}_{i} & :=\pi_{i}+R_{i}, \quad R_{i}:=r_{i} q_{i} \\
& =(P(Q)-c+\epsilon) q_{i}, \quad i \in\{w, l\} .
\end{aligned}
$$

LEMMA 2 Aggregate gross profits are strictly increasing in $\bar{c}$.

Proof Aggregate gross profits are equal to $(P(Q)-c+\epsilon) Q$. By assumption 1 , aggregate gross profits are concave in $Q$, and since the innovation is not drastic, the equilibrium $Q$ is greater than the monopoly output. Therefore, the sum of gross profits is declining in $Q$, and since $Q$ is decreasing in $\bar{c}$, by Lemma 1, aggregate gross profits are increasing in $\bar{c}$.

LEMMA 3 If losers are crowded out, i.e. $P \leq c$, aggregate gross profits are decreasing in $k$.

\footnotetext{
${ }^{5}$ With slight abuse of notation we use the same symbol for outputs and equilibrium strategies, whenever there is no risk of confusion.

${ }^{6}$ Since $(P(Q) Q)^{\prime}$ is decreasing and $P^{\prime}(Q)<0$, it follows that $n P(Q)+P^{\prime}(Q) Q$ is also decreasing. Together with the fact that $\lim _{Q \rightarrow 0}\left(P(Q)+P^{\prime}(Q) Q\right)=P(0)>c$ we conclude that a positive solution $Q>0$ exists and is unique. Given $Q$, existence and uniqueness of $q_{l}$ follow immediately.
} 
PROOF If losers are crowded out, then the market is a symmetric $k$-firm oligopoly with aggregate gross profits equal to $k \bar{\pi}_{w}$. Obviously, reducing the number of firms in a symmetric oligopoly increases the sum of gross profits for $k \geq 1$. The profit is maximized in a monopoly, i.e. $k=1$.

Finally, we mention that there are also subgames in which some firms have no license at all. In those subgames one must distinguish between three kinds of players: winners, losers who exercise the royalty option, and losers who do not. In that case, the Cournot equilibrium solves an additional KuhnTucker condition concerning those who have no license, where one has to change the definition of average marginal cost accordingly. Of course, in the equilibrium those losers who do not exercise the royalty option are worse off. A special case is the subgame where no loser has exercised the royalty option. This is particularly relevant if exercising the royalty is unattractive because $r_{l}>\epsilon$.

ROYALTY LICENSING SUBGAMES After the auction has selected $k$ winners and $n-k$ losers, each loser can either accept the royalty contract with the royalty rate $r_{l}$ or refuse and operate under the initial marginal cost $c$. The SPE of the royalty licensing subgame is to accept if $r_{l}<\epsilon$, to reject if $r_{l}>\epsilon$, whereas losers are indifferent if $r_{l}=\epsilon$. However, as will become clear, rejection cannot be part of the SPE of the entire game. Therefore, in the SPE of the entire game losers exercise the royalty option if and only if $r_{l} \leq \epsilon$.

AUCTION SUBGAMES In the auction subgames each firm is asked to bid on at most one of $k$ license contracts in a lowest price auction (possibly with a minimum bid) where the $k$ highest bidders win, in case of a tie winners are selected at random, and each winner pays the lowest winning bid. ${ }^{7}$ Each firm knows that if it does not obtain a license in the auction it can subsequently exercise the royalty contract option.

In equilibrium, all licenses are sold since $r_{w}<\epsilon$, provided the minimum bid is not set too high. Since firms have complete information, the equilibrium bid is equal to the value of the auctioned license contract. That value is the difference between the profit of a winner and that of a loser. In computing that value it is crucial to distinguish between the case when licenses are rationed because the innovator restricts the number of licenses $(k<n)$ and when they are not rationed $(k=n)$. If $k=n$, bidders' participation in the auction affects the structure of the subsequent oligopoly game, whereas if $k<n$ that market structure cannot be affected by an individual bidder.

As we show below, a minimum serves no purpose if $k<n$. However, if $k=n$, the innovator can only earn revenue if he charges a minimum bid. In that

\footnotetext{
${ }^{7}$ Instead of using this slightly unusual pricing rule one could use for example a discriminatory auction where each winner pays his bid or a uniform price auction in which winners pay the highest losing bid. The disadvantage of these rules is that they have multiple asymmetric equilibria.
} 
case, we assume that the innovator applies the most profitable minimum bid, which is equal to firms' maximum willingness to pay, $b_{0}:=\pi_{w}(n)-\pi_{l}(n-1)$ (as in Kamien (1992)).

LEMMA 4 Suppose $k$ licenses with $r_{w}<\epsilon$ are auctioned, losers have the option to sign a royalty contract with the royalty rate $r_{l}>r_{w}$, and the auctioneer applies the minimum bid, $b_{0}$, if he sets $k=n$. The SPNE strategy of each firm is to participate in the auction and bid an amount equal to ${ }^{8}$

$$
b(k)=\left\{\begin{array}{lll}
\pi_{w}(k)-\pi_{l}(k) & \text { if } \quad k \leq n-1 \\
\pi_{w}(n)-\pi_{l}(n-1) & \text { if } \quad k=n .
\end{array}\right.
$$

Proof The value of an auctioned license is the difference between $\pi_{w}$ and $\pi_{l}$.

If $k<n$ no firm can unilaterally influence the subsequent market structure composed of $k$ winners and $n-k$ losers. Because if a firm refrains from bidding, another bidder wins the license. Therefore, if $k<n$, each firm knows that it faces a given market structure in the subsequent oligopoly game, and therefore should participate in the auction and bid the amount $\pi_{w}(k)-\pi_{l}(k)$.

This is different if $k=n$. Then, a firm that refrains from bidding thus changes the subsequent market structure from $n$ winners and no loser to $n-1$ winners and one loser. In that case the auction can only generate revenue if the innovator sets an appropriate minimum bid because otherwise firms can buy a license with a zero bid. (Whereas, if $k<n$, a minimum bid serves no purpose.) Therefore, the innovator sets a minimum bid equal to firms' maximum willingness to pay, $\pi_{w}(n)-\pi_{l}(n-1)$, and firms participate in the auction and bid that amount.

\section{THE EQUILIBRIUM MECHANISM}

The innovator chooses the licensing policy $\left(k, r_{w}, r_{l}\right)$ that maximizes his income, $\Pi$, which is composed of auction revenue and royalty income from winners and losers. This format includes the standard mechanisms analyzed in the literature as special cases. In the SPNE all firms participate in the auction and bid according to the bid function $b(k)$ and all losers exercise the royalty option. Therefore,

$$
\begin{aligned}
\Pi & =k b(k)+k r_{w} q_{w}+(n-k) r_{l} q_{l} \\
& =k\left(\pi_{w}-\pi_{l}\right)+k R_{w}+(n-k) R_{l} \\
& =k\left(\bar{\pi}_{w}-\bar{\pi}_{l}\right)+n R_{l} .
\end{aligned}
$$

\footnotetext{
${ }^{8}$ There, $\pi_{w}(k), \pi_{l}(k)$ denote the equilibrium profits in the Cournot subgame with $k$ winners and $n-k$ losers who exercise the royalty option.
} 
PROPOSITION 1 (OPTIMAL LICENSING) The optimal licensing policy exhibits:

1) full dissemination of the innovation to all firms

2) restrictive license auction, $1 \leq k \leq n-1$

3) maximum royalty rate for losers, $r_{l}=\epsilon$

4) an asymmetric oligopoly is created (i.e. no firm is crowded out).

The proof is in a sequence of Lemmas, below.

\subsection{Pure royalty contracts are not optimal}

Using a linear model, Kamien (1992) already showed that license auctions dominate pure royalty licensing. However, as Sen (2005) pointed out recently, if one takes into account that the number of licenses must be an integer (which has been ignored in the literature), pure royalty contracts may be more profitable than license auctions. However, as we now show, pure royalty contracts are not optimal, even if one accounts for the integer constraint concerning $k$. As our proof indicates, the proposed royalty option to losers plays a key role in establishing this result.

LEMma 5 (EXClusion of PURE Royalty ConTRACTS) Pure royalty licensing, i.e. $k=0$, is not optimal (even if one accounts for the integer constraint concerning $k$ ).

Proof Consider royalty licensing, i.e. $k=0$ at the rate $r_{l} \in(0, \epsilon]$ (royalty rates greater than $\epsilon$ are never accepted). We prove the assertion by showing that the mechanism $\left(k=1, r_{w}=0, r_{l}\right)$, that issues one license and offers the same royalty rate $r_{l}$ to all losers is more profitable for the innovator.

Denote firms' equilibrium outputs under royalty licensing and the stated mechanism by $q_{R}$ resp. $\left(q_{w}, q_{l}\right)$, the associated aggregate outputs by $Q_{R}:=$ $n q_{R}, Q_{M}:=q_{w}+(n-1) q_{l}$, and the equilibrium prices by $p_{R}, p_{M}$. Then, the innovator's profit is

$$
\begin{aligned}
\Pi\left(1,0, r_{l}\right) & =\left(p_{M}-c+\epsilon\right) q_{w}-\left(p_{M}-c+\epsilon-r_{l}\right) q_{l}+r_{l}(n-1) q_{l} \\
& =\left(p_{M}-c+\epsilon-r_{l}\right)\left(q_{w}-q_{l}\right)+r_{l} Q_{M} \\
& >r_{l} Q_{M}>r_{l} Q_{R}=\Pi\left(0,0, r_{l}\right)
\end{aligned}
$$

The first inequality follows from three facts: 1) the innovation is non-drastic and therefore the one licensee cannot crowd out other firms which assures that the Cournot equilibrium price $p_{M}$ remains above the marginal cost $c$, $p_{M}>c$; hence, royalty income from losers is generated; 2) $\epsilon \geq r_{l}$; 3) $q_{w}>q_{l}$ because the licensee has lower marginal cost. To understand the second inequality, note that both regimes induce an $n$-firms oligopoly, where one firm has lower marginal cost in the modified license auction, which gives rise to a higher aggregate output, as we show in Lemma 1. 


\subsection{Why it is not optimal to auction $k=n$ licenses}

If the innovator auctions $k=n$ licenses, he sets a minimum bid equal to the amount $\pi_{w}(n)-\pi_{l}(n-1)$ (where, of course, $\pi_{l}(n-1)$ can be equal to zero), and every firm bids that amount, as already explained in Lemma 4. We now show that such a mechanism is not optimal. Instead, the optimal mechanism involves restrictive licensing, $k<n$.

LEMMA 6 The optimal mechanism sets $k<n$ (even if one accounts for the integer constraint concerning $k$ ).

Proof Consider the mechanism $m:=\left(n, r_{w}, r_{l}\right)$, supplemented by a minimum bid equal to $\pi_{w}(n)-\pi_{l}(n-1)$. We show that the modified mechanism $m^{\prime}:=\left(n-1, r_{w}, r_{l}\right)$, that differs from $m$ only by replacing $k=n$ by $k=n-1$, is more profitable for the innovator:

$$
\begin{aligned}
\Pi(m): & =n\left(\bar{\pi}_{w}(n)-\bar{\pi}_{l}(n-1)+R_{l}(n-1)\right) \\
\Pi\left(m^{\prime}\right): & =(n-1)\left(\bar{\pi}_{w}(n-1)-\bar{\pi}_{l}(n-1)\right)+n R_{l}(n-1) \\
\Pi\left(m^{\prime}\right)-\Pi(m) & =(n-1) \bar{\pi}_{w}(n-1)+\bar{\pi}_{l}(n-1)-n \bar{\pi}(n)>0 .
\end{aligned}
$$

The latter inequality holds because (11) compares the sums of gross profits in two different markets: one with $n-1$ winners and 1 loser and the other with $n$ winners. Obviously, the former exhibits a higher average marginal cost, $\bar{c}$, and hence a greater sum of gross profits, by Lemma 2.

\subsection{Which royalty rate for losers?}

LEMMA 7 (ROYALTY RATE FOR LOSERS) The optimal mechanism sets the royalty rate for losers equal to the cost reduction, $r_{l}=\epsilon$.

Proof Suppose the royalty rate for losers is raised from $r_{l}$ to $r_{l}^{\prime}$ with $r_{l}<r_{l}^{\prime} \leq \epsilon$. Assume losers are not crowded out (we show in Lemma 10 that crowding out is not optimal). Therefore, the subsequent market game is an asymmetric oligopoly, characterized in (3)-(5), with a higher average marginal cost, $\bar{c}^{\prime}>\bar{c}$. Denote all equilibrium values induced by that change by a prime, the equilibrium royalty incomes by $R_{i}:=r_{i} q_{i}, i \in\{w, l\}$, and gross profits (before deducting royalties) by $\bar{\pi}_{i}:=\pi_{i}-R_{i}$.

Recall that, by (8), $\Pi:=k\left(\bar{\pi}_{w}-\bar{\pi}_{l}\right)+n R_{l}$, and use the fact that the sum of gross profits is increasing in $\bar{c}$, by Lemma 2 , and that the increased royalty rate $r_{l}^{\prime}$ reduces losers' equilibrium profits, and one concludes,

$$
\begin{aligned}
\Pi^{\prime}-\Pi & =k\left(\left(\bar{\pi}_{w}^{\prime}-\bar{\pi}_{w}\right)-\left(\bar{\pi}_{l}^{\prime}-\bar{\pi}_{l}\right)\right)-n\left(R_{l}-R_{l}^{\prime}\right) \\
& >(n-k)\left(\bar{\pi}_{l}-\bar{\pi}_{l}^{\prime}\right)-k\left(\bar{\pi}_{l}^{\prime}-\bar{\pi}_{l}\right)-n\left(R_{l}-R_{l}^{\prime}\right), \quad \text { by Lemma } 2 \\
& =n\left(\bar{\pi}_{l}-\bar{\pi}_{l}^{\prime}\right)-n\left(R_{l}-R_{l}^{\prime}\right) \\
& =n\left(\pi_{l}-\pi_{l}^{\prime}\right) \\
& >0 .
\end{aligned}
$$

Therefore, the optimal $r_{l}$ is equal to the highest rate that is not rejected: $r_{l}=\epsilon$. 
By charging maximum royalties to losers, the industry output is moved towards the monopoly output. This allows the innovator to extract maximum rent from the winners. Of course, raising royalties for losers may also imply lower royalty income from them. But this loss is more than compensated by the increased rent extracted from winners.

\subsection{Why the optimal mechanism reduces to the choice of $\bar{c}$}

We now show that the optimal mechanism, $\left(k, r_{w}, r_{l}\right)$, can be reduced to the optimal choice of average marginal cost, $\bar{c}$. The To prepare the proof, we first exclude the optimality of excessive crowding out. Excessive crowding out means that the mechanism gives rise to an equilibrium price lower than losers' marginal cost, $P<c$.

LEMMA 8 (NO "EXCESSIVE CROWDING OUT") The optimal mechanism exhibits $P \geq C$.

Proof Suppose, per absurdum, that the optimal mechanism involves a price below $c$, which implies $q_{l}=0$. In that case the innovator's profit is $\Pi=k \bar{\pi}$, i.e. the innovator collects the sum of winners' gross profits. Then, by Lemmas 2 and 3, the innovator's profit can be increased by raising $\bar{c}$ or by lowering $k$. In the present context the only way to raise $\bar{c}$ is to raise $r_{w}$ up to the limit where $P=c$. It is optimal to raise that limit as much as possible, which implies $r_{l}=\epsilon$. Thus, a price below $c$ is not optimal. In turn, lowering $k$ is a move towards the monopoly outcome, i.e. it raises the price. This increases the innovator's profit up to the point where $P=c$. Again, $P<c$ is not optimal.

LEMMA 9 The optimal choice of mechanism reduces to choosing the average marginal cost, $\bar{c}$ that maximizes

$$
\Pi(\bar{c}):=(P(Q(\bar{c}))-c)\left(Q(\bar{c})-n q_{L}(\bar{c})\right)+Q(\bar{c}) \epsilon .
$$

Proof The innovator's profit (8) can be written in the form (13) if one replaces $q_{w}$ by $Q$ and $q_{l}$ and uses the result $r_{l}=\epsilon$. By Lemma 8, excessive crowding out is not optimal. Therefore, the equilibrium solution of the Cournot market game, $\left(Q, q_{l}\right)$, solves equations (3) and (4). These equilibrium outputs are exclusively a function of $\bar{c}$. It follows that $\Pi$ is exclusively a function of $\bar{c}$.

Using the definition of $\bar{c}$ it follows immediately:

COROLLARY 1 (DEGREE OF FREEDOM) The optimal mechanism has a degree of freedom. Given the optimal $\bar{c}$, all combinations of $\left(k, r_{w}\right)$ that satisfy the condition

$$
\bar{c}=c-\frac{k}{n}\left(\epsilon-r_{w}\right) .
$$

with $k \in[1, n-1]$ and $r_{w}<\epsilon$ are optimal.

This trade-off is illustrated in Figure 1. 


\subsection{Why is it not optimal to "crowd out" losers?}

LEMMA 10 (NO "CROWDING OUT") In the optimal mechanism winners and losers coexist, i.e. $P>c$, and $q_{w}, q_{l}>0$.

Proof We have already excluded a price lower than $c$ (excessive crowding out). It only remains to be shown that a mechanism that induces a price equal to $c$ cannot be optimal either.

Suppose, per absurdum, that the optimal mechanism involves a price equal to $c$, which implies that $q_{l}=0$ is an interior solution of the losers' best-reply problem. Denote the $\bar{c}$ that gives rise to an equilibrium price equal to $c$ by $\bar{c}^{*}$. Then, one must have:

$$
\begin{aligned}
0=\left.\frac{\partial \Pi}{\partial \bar{c}}\right|_{\bar{c}=\bar{c}^{*}} & =\left(\epsilon+Q P^{\prime}\right) Q^{\prime} \quad(\text { by }(13)) \\
& =\left(\epsilon+n\left(\bar{c}^{*}-P\right)\right) Q^{\prime} \quad(\text { by }(3)) \\
& =\left(\epsilon+n\left(\bar{c}^{*}-c\right)\right) Q^{\prime} \quad(\text { since } P=c) .
\end{aligned}
$$

Therefore, $\bar{c}^{*}=c-\frac{\epsilon}{n}$. Using the definition of $\bar{c}$, all combinations of $\left(k, r_{w}\right)$ that solve the condition $k\left(\epsilon-r_{w}\right)=\epsilon$ are optimal. In particular, $\left(k=1, r_{w}=\right.$ 0 ) is optimal. However, together with $P=c$, this contradicts the assumption of a non-drastic innovation. Recall, a non-drastic innovation implies that the monopoly price is above the pre-innovation cost $c$.

\subsection{Why the proposed mechanism is superior}

Compare the proposed optimal mechanism with the mechanisms considered in the literature. As we already pointed out, the class of mechanisms considered here includes all the other mechanisms as special cases. Therefore, our proposed optimal mechanism cannot be inferior. In Lemmas 6, 10 and 7 we have shown that it is optimal to chose $k<n$, to not crowd-out losers, $q_{l}>0$, and to set $r_{l}=\epsilon$. Therefore, unlike all these mechanisms, the proposed optimal mechanism generates royalty income from losers. This proves strict superiority, as long as one ignores that the number of licenses must be an integer.

\subsection{Irrelevance of the integer constraint}

We have shown that the optimal mechanism exhibits $k \in[1, n-1], r_{w}<\epsilon$, $r_{l}=\epsilon$ and no crowding out. Therefore, the optimal average marginal cost is bounded by $\bar{c} \in(c-\epsilon, c)$. Now we show that the integer constraint concerning the number of contracts, $k$, is irrelevant in the sense that it can always be accommodated without affecting the innovator's equilibrium income.

Corollary 1 suggests that the degree of freedom allows us to implement the optimal $\bar{c}$ by choosing an arbitrary integer $1 \leq k \leq n-1$. But is this always feasible? 
An integer $k$ is feasible for a given optimal $\bar{c}$ if the corresponding royalty rate $r_{w}=\epsilon-\frac{n}{k}(c-\bar{c})$ is smaller than $\epsilon$. By Lemma 5 , which excludes $k=0$, one has $\bar{c}<c$ and thus $r_{w}<\epsilon$. Therefore, the optimal $\bar{c}$ can always be implemented with an integer $k$, without loss in profit, as illustrated in Figure 1.

This also indicates that royalties for winners are essentially useful to "fine tune" the optimal mechanism in the face of the integer constraint concerning $k$. If one ignores that integer constraint, royalties for winners serve no purpose.

COROLLARY 2 (STRICT SUPERIORITY) The optimal licensing policy is strictly more profitable than all standard licensing mechanisms such as pure royalty contracts, standard license auctions, auctions of royalty contracts, and takeit-or-leave-it two-part tariffs.

We mention that if one does not include the proposed royalties for losers, as in the mechanism analyzed by Sen and Tauman (2007), the innovator's profit is not exclusively a function of $\bar{c}$, and one does not obtain the above degree of freedom. As a result one faces an integer problem that generically entails a loss in profit. The same holds true if one does not include royalties for winners. Therefore, adding royalties for winners and losers, is crucial for the above stated irrelevance of the integer constraint.

\subsection{Illustration: Linear Demand}

The literature on patent licensing usually assumes a linear model with $P:=$ $a-Q, a>c$. Due to the prominence of this model, we briefly illustrate our findings for that case.

In the linear model the optimal $\bar{c}$ is equal to $\bar{c}=c-\frac{a-c+\epsilon}{2 n}$, and the optimal mechanism $\left(k, r_{w}, r_{l}\right)$ is:

$$
k \in\{1, \ldots, n-1\}, \quad\left(r_{w}, r_{l}\right)=\left(\epsilon-\frac{a-c+\epsilon}{2 k}, \epsilon\right)
$$

Moreover, $K=\frac{a-c}{\epsilon}$. Specifically, setting $k=n-1$ gives $r_{w}=\frac{2 n-3-K}{2(n-1)} \epsilon$. For $K>2 n-3$ ("weak" innovations), $r_{w}$ is negative, i.e. winners' outputs are subsidized.

If one ignores the integer constraint the royalty rate for winners serves no purpose and

$$
\left(k, r_{w}, r_{l}\right)=\left(\frac{K+1}{2}, 0, \epsilon\right)
$$

is an optimal mechanism.

\section{DISCUSSION}

\subsection{Welfare comparisons}

Welfare is completely determined by the adopted technologies and aggregate output. In the equilibrium of the Cournot subgame aggregate output 


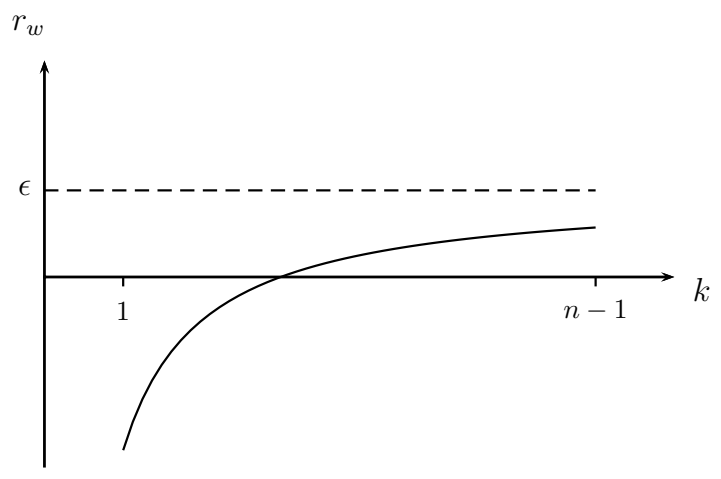

Figure 1: Optimal combinations of $\left(k, r_{w}\right)$ for $(a, n, c, \epsilon)=(1,20, .4, .05)$

is exclusively a function of the average marginal cost $\bar{c}$ if no crowding out occurs; whereas if crowding out occurs, aggregate output is exclusively a function of $c_{w}$.

Under the proposed mechanism the new technology is used by all firms; hence, social marginal cost is equal to $c-\epsilon$. No firm is crowded out, and thus the equilibrium aggregate output is determined by $\bar{c} \in(c-\epsilon, c)$ (see (3)). Therefore, welfare is greater than before the innovation, regardless of which optimal combination of $k$ and $r_{w}$ is applied.

Under optimal pure royalty licensing (with royalty rate $r$ ) the new technology is also used by all firms and hence social marginal cost is also equal to $c-\epsilon$. Aggregate output is completely determined by $c-\epsilon+r$. Therefore, if $r=\epsilon$ (which is optimal in the standard linear model), welfare is smaller than in the proposed mechanism, although greater than before the innovation.

The standard optimal license auction without royalties has several equilibrium outcomes, depending on the magnitude of the innovation (see Kamien et al. (1992)). For sufficiently strong innovations (reflected in a small number $K$ ), some firms are crowded out. All remaining firms use the new technology and social marginal cost is equal to $c-\epsilon$. Crowding out implies $P \leq c$. Whereas under our proposed mechanism, no firm is crowded out and $P>c$. Hence, in this case, the standard license auction entails greater welfare than our proposed mechanism. For weak innovations, the optimal standard auction does not crowd out. If all firms get a license, $k=n$, social marginal cost is equal to $c-\epsilon$ and the auction achieves the maximum welfare obtainable under Cournot competition. ${ }^{9}$

\subsection{Why an auction instead of two-part tariffs?}

One may ask: why is it not optimal to make a take-it-or-leave-it offer instead of an auction? Answering this question helps to understand the fundamen-

\footnotetext{
${ }^{9}$ If $k<n$, social marginal cost is between $c$ and $c-\epsilon$, since those who do not get a license do not get the new technology. Nevertheless, the welfare comparison is ambiguous.
} 
tal role of the auction in the present context.

Suppose the innovator makes a take-it-or-leave-it offer to each firm that gives firms the same allocation and transfers as the equilibrium of the auction. Then, a designated winner has an incentive to deviate and not accept the contract, for the following reason:

If the winner accepts, his payoff is the same as that of a firm that accepts a loser contract, by design of the auction. However, if he rejects the offer, each loser is made better off because one firm with low marginal cost has been replaced by one firm with high marginal cost. The deviator is now one of those losers. Therefore, his payoff is increased.

Why does this logic not apply if the innovator employs an auction to sell winner contracts? The reason is simple. If a firm does not bid or a designated winner deviates and rejects the offer, another bidder will become a winner instead. Therefore, the industry structure remains unchanged. Hence deviation does not pay.

Of course, deviation never pays for a loser because if a loser does not exercise the royalty option, the industry structure is not changed at all.

This explains why using auctions to sell a restricted number of licenses is a clever way to reduce the bargaining power of licensees, more than what the innovator could achieve with an ultimatum offer. ${ }^{10}$

\subsection{Can a combinatorial auction do even better?}

One may think that a combinatorial auction may be even more profitable for the innovator. However, this is not true, for the following reason.

Suppose the auctioneer runs the following combinatorial auction (ignoring royalties to winners): Each firm is invited to make a bid contingent on getting one out of $k \in\{1,2, \ldots, n\}$ licenses. After all bids have been submitted, the auctioneer selects the most profitable $k$, awards $k$ licenses, and all winners pay their bids. In equilibrium, bids are such that bidders are indifferent between winning and losing, as in (7). Of course, bids differ for different values of $k$, reaching a maximum profit of the innovator at some $k$. The auctioneer selects that $k$, which is precisely the number of licenses that he auctions in our simple auction. We conclude that using combinatorial auctions cannot further boost the innovator's profit. ${ }^{11}$

\subsection{The "chutzpah mechanism" revisited}

Having characterized the optimal mechanism in the class $\left(k, r_{w}, r_{l}\right)$, one may ask: is it the best the innovator can do or is there a superior mechanism?

\footnotetext{
${ }^{10}$ Of course, two-part tariffs are equally good if the innovator can credibly threaten to withdraw the innovation if one or more firms do not accept the offered two-part tariffs. In this light, the advantage of the auction is that it works without such "collective punishment" threats.

${ }^{11}$ Note, however, that combinatorial auctions are attractive if firms are heterogeneous, and firms are allowed to make bids contingent on who gets the innovation.
} 
Following Kamien (1992), Kamien et al. (1992) we address this question by looking at an extreme reference point that can be implemented by an appropriately generalized "chutzpah mechanism". ${ }^{12}$ That reference point can be useful as an upper bound of the innovator's profit.

Taking $\left(k, r_{w}, r_{l}\right)$ as given, the innovator cannot possibly extract more than the total industry gross profit, $\sum \bar{\pi}:=k \bar{\pi}_{w}(k)+(n-k) \bar{\pi}_{l}(k)$. However, each firm can assure itself at least a (net) profit equal to $\pi_{l}(n-1)$, since $\pi_{l}(k) \geq \pi_{l}(n-1)$, for all $k \geq n-1$. Therefore, the innovator cannot extract more than:

$$
\tilde{\Pi}(k):=\sum \bar{\pi}-n \pi_{l}(n-1)
$$

Comparing this with (8) one finds, after a bit of rearranging,

$$
\tilde{\Pi}(k)-\Pi(k)=n\left(\pi_{l}(k)-\pi_{l}(n-1) \geq 0,\right.
$$

with equality if and only if $k=n-1$. Therefore, if one chooses the optimal proposed mechanism, $\left(k, r_{w}, r_{l}\right)$, the equilibrium innovator profit, $\Pi$, is bounded from above:

$$
\Pi \leq \tilde{\Pi}(k) .
$$

This upper bound can be reached by our proposed mechanisms for $k=n-1$, which is an optimal number of licenses in the proposed mechanism.

Of course, the innovator can reach $\tilde{\Pi}(k)$ for all other $k$ and even higher profits if he can extort additional transfers by threatening to trigger a collective penalty in the event when at least one firm fails to pay. This can be achieved by a generalized "chutzpah mechanism", which may be useful as a benchmark but offers no practically relevant guidance. ${ }^{13}$

\subsection{Bertrand competition and differentiated goods}

One may wonder to what extent our results rely on the assumptions of Cournot competition and homogeneous goods. If one maintains the homogeneous goods assumption but replaces Cournot by Bertrand competition, the optimal licensing mechanism obviously gives rise to monopoly, as already pointed out by Kamien (1992). However, as it is generally the case, the combination of homogeneous goods with Bertrand competition is only a borderline case. Therefore, Bertrand competition can only yield plausible results in the context of heterogenous goods.

If goods are sufficiently heterogeneous substitutes, each firm has its own market niche even if there is some dispersion of costs. Therefore, crowding

\footnotetext{
${ }^{12}$ The "chutzpah mechanism" was introduced by Kamien et al. (1990).

${ }^{13}$ There, 1$)$ the innovator offers the mechanism $\left(k, r_{w}, r_{l}=\epsilon\right)$ supplemented by a participation fee equal to $\bar{\pi}_{l}(k)-\bar{\pi}_{l}(n-1)$, and the proviso that this offer is valid only if all $n$ firms pay the requested participation fee. 2) If a bidder refuses to pay the participation fee, the innovator calls off the auction 1), refunds the collected participation fees (if any), and then 3 ) runs the unconditional license auction with royalties: $\left(k, r_{w}, r_{l}\right)=\left(n-1, r_{w}, r_{l}=\epsilon\right)$.
} 
out should be of less concern. Exclusive licensing is profitable to the innovator, as in the above model, since granting a license to a firm inflicts a negative externality on all other firms. Similarly, adding the royalty option to losers unambiguously increases the innovator's profit, since granting that option does not affect the payoffs of winners, and thus does not affect the equilibrium bids for the license. This suggests that the same logic that drives the superiority of the proposed mechanism in the above model applies equally well to Bertrand competition with sufficiently heterogeneous substitutes.

However, if goods are complements, the picture should change more drastically. In that case, firms mutually benefit from each others' cost reduction, since one firm's price reduction raises the other firms' demand. Therefore, giving one firm a license does not inflict a negative externality upon others which in turn implies that one cannot induce higher bids by restricting the number of licenses. This reasoning applies regardless of whether there is either Cournot or Bertrand competition. Therefore, one should expect that the attraction of auctioning a limited number of licenses vanishes, and it should be optimal to give all firms a license $(k=n)$.

\subsection{Further extensions}

The literature has suggested that pure royalty licensing can be justified by uncertainty concerning the success of the innovation. This is due to the fact that royalty licensing entails a sharing of that risk between innovator and licensees. In this regard, the proposed mechanism could perform even better than pure royalty licensing. If firms have different degrees of risk aversion, the more risk averse firms would tend to lose the auction and then exercise the royalty licensing option. And the less risk averse firms would tend to win one of the fixed-fee licenses in the auction. In this way, the proposed mechanism would allow the innovator to gain from price discrimination between firms with different degrees of risk aversion.

Aoki and Tauman (2001) have explored how spillovers affect the optimal license auction. Spillovers reduce the royalty dividends collected by the innovator, since part of the cost reduction due to the innovation is already available without licensing. This suggests that spillovers make the option to sign a royalty licensing contract less valuable. But it should not eliminate that benefit altogether, unless the complete cost reduction spills over.

\section{REFERENCES}

Aoki, R., Tauman, Y., 2001. Patent licensing with spillovers. Economics Letters $73,125-130$.

Beggs, A. W., 1992. The licensing of patents under asymmetric information. International Journal of Industrial Organization 10, 171-191. 
Brousseau, E., Coeurderoy, R., Chaserant, C., 2007. The governance of contracts: Empirical evidence on technology licensing agreements. Journal of Institutional and Theoretical Economics 163, in print.

Gallini, N., Wright, B., 1990. Technology transfer under asymmetric information. Rand Journal of Economics 21 (1), 147-160.

Hernández-Murillo, R., Llobet, G., 2006. Patent licensing revisited: Heterogeneous firms and product differentiation. International Journal of Industrial Organization 24, 149-175.

Jehiel, P., Moldovanu, B., 2000. Auctions with downstream interaction among buyers. Rand Journal of Economics 31, 768-791.

Kamien, M., Tauman, Y., 1984. The private value of a patent: a game theoretic analysis. Journal of Economics 4, 93-118.

Kamien, M. I., 1992. Patent licensing. In: Aumann, R., Hart, S. (Eds.), Handbook of Game Theory. Vol. I. Elsevier Science, pp. 331-354.

Kamien, M. I., Oren, S., Tauman, Y., 1992. Optimal licensing of cost-reducing innovation. Journal of Mathematical Economics 21, 483-508.

Kamien, M. I., Tauman, Y., 1986. Fee versus royalties and the private value of a patent. Quarterly Journal of Economics 101, 471-491.

Kamien, M. I., Tauman, Y., 2002. Patent licensing: The inside story. The Manchester School 70 (1), 7-15.

Kamien, M. I., Tauman, Y., Zamir, S., 1990. On the value of information in a strategic conflict. Games and Economic Behavior 2, 129-153.

Katz, M. L., Shapiro, C., 1985. On the licensing of innovations. Rand Journal of Economics 16 (4), 504-520.

Katz, M. L., Shapiro, C., 1986. How to license intangible property. Quarterly Journal of Economics 101, 567-589.

Macho-Stadler, I., Pérez-Castrillo, D., 1991. Contrats de licences et asymmétrie d'information. Annales D'Economie et de Statistique 24, 189-208.

Muto, S., 1993. On licensing policies in Bertrand competition. Games and Economic Behavior 5, 257-267.

Rostoker, M., 1984. A survey of corporate licensing. IDEA 24, 59-92.

Sen, D., 2005. Fee versus royalty reconsidered. Games and Economic Behaviour 53, 141-147.

Sen, D., Tauman, Y., 2007. General licensing schemes for a cost-reducing innovation. Games and Economic Behavior 59, 163-186. 
Vishwasrao, 2007. Royalties vs. fees: How do firms pay for foreign technology? International Journal of Industrial Organization (in press).

Wang, X. H., 1998. Fee versus royalty licensing in a Cournot duopoly model. Economics Letters 60, 55-62. 